\title{
Combined crystallochemical and quantum-chemical search for new high-valent chalcogen-containing ionic conductors
}

\author{
Ye. Morkhova ${ }^{1,2}$, A. Kabanov ${ }^{1,2}$, T. Leisegang ${ }^{2,3}$, M. Rothenberger ${ }^{3}$, V. Blatov ${ }^{1,2}$

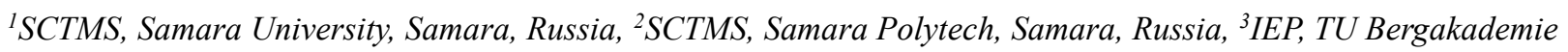 \\ Freiberg, Freiberg, Germany
}

eliztimofeeva@mail.ru

Improvement of existing batteries is a hot topic due to both the rapid spread of mobile technologies and the impetuous growth of the electric vehicle sector. The commonly used lithium-ion batteries (LIB) have a number of well-known disadvantages: flammability and high lithium price due to limited natural resources. The moderate capacity of LIBs is a further challenge for high-performance mobile devices. Theoretically, all-solid-state batteries based on high-valent working ions, such as magnesium, zinc or aluminum, can have higher volumetric capacities compared to LIBs [1].

We report the results of the high-throughput search for new solid electrolytes (SE) and cathode materials for high-valent metal-ion batteries. We focused on Mg-, Ca-, Zn- and Al-containing ternary and quaternary chalcogenides. Theoretically, S-, Se- or Tecontaining compounds should exhibit higher cation conductivities than their oxygen analogues. It can be explained by a lower degree of ionicity in chalcogenides in comparison to oxides [2]. Our study was performed by using a well-established high-throughput screening algorithm [3]. The algorithm consists of three main steps: (a) fast topological-geometrical screening; (b) bond valence site energy (BVSE) modeling for a preliminary quantitative estimation and (c) precise quantum-chemical modeling of ionic transport.

All ternary and quaternary $\mathrm{Mg}, \mathrm{Ca}, \mathrm{Zn}$ and $\mathrm{Al}$ chalcogenides (1572 structures) were extracted from the ICSD (version 2020/1). Among them, a group of promising cation conductors with 1D-, 2D-, or 3D-migration maps was identified by using the Voronoi partitioning algorithm as implemented in the ToposPro package [4]. We obtained $72 \mathrm{~S}-, 30 \mathrm{Se}$ - and 11 Te-containing high-valent ion conductors. The BVSE method was utilized for determination of migration energies of all species in the compounds, and a group of most promising compounds with migration barriers $E_{m} \leq 0.5 \mathrm{eV}$ and the difference in the migration energies with other ions $\Delta E_{m} \geq 0.5$ $\mathrm{eV}$ was selected. This group includes, in particular, $\mathrm{MgLu}_{2} \mathrm{Se}_{4}, \mathrm{MgHo}_{2} \mathrm{Se}_{4}, \mathrm{ZnLa}_{3} \mathrm{GaSe}_{7}, \mathrm{Al}_{5.9} \mathrm{SnTe}_{9.892}, \mathrm{Al}_{2} \mathrm{Be}_{2} \mathrm{La}_{6} \mathrm{~S}_{14}, \mathrm{Al}_{3.3} \mathrm{Dy}_{6} \mathrm{~S}_{14}$, $\mathrm{Al}_{3.3} \mathrm{La}_{6} \mathrm{~S}_{14}$ compounds. In a final step, the density functional theory (DFT) modeling was carried out for the structures with lowest $E_{m}$ compounds. The Nudged Elastic Band (NEB) method was used as implemented in the VASP package [5]. Figure 1 shows a good agreement of migration maps between the three applied approaches.

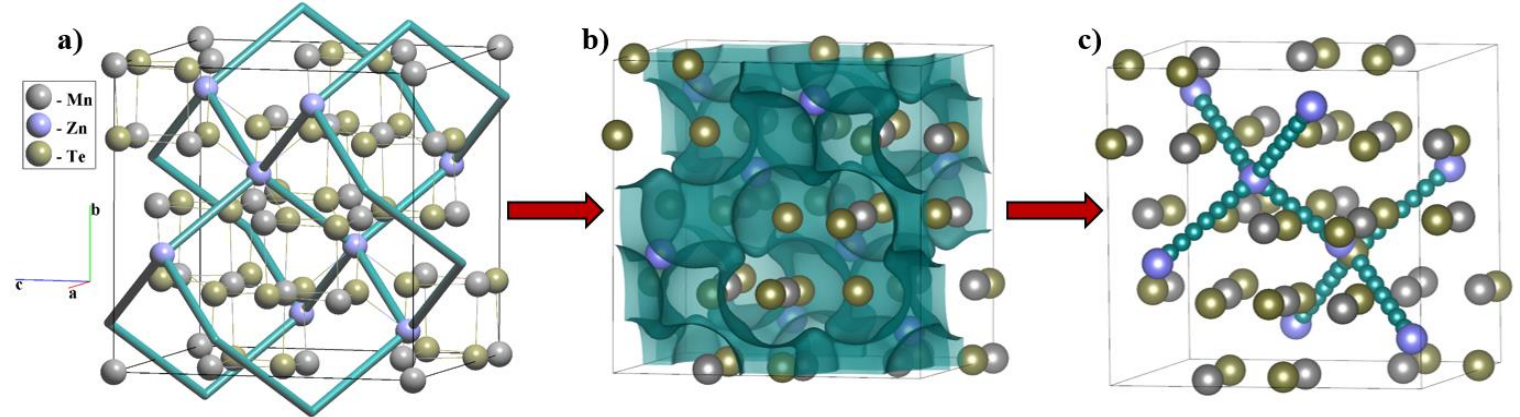

Figure 1. 3D $\mathrm{Zn}^{2+}$-migration map for $\mathrm{ZnMn}_{2} \mathrm{Te}_{4}$ compound in terms of crystallochemical analysis (a), bond valence site energies (b) and quantumchemical modeling (c).

All results were uploaded to the web site http://batterymaterials.info, where they are available free of charge.

[1] Margilies, L., Kramer, M. J., McCallum, R. W., Kycia, S., Haeffner, D. R., Lang, J. C., Goldman, A. I. (1999). Rev. Sci. Instrum. 70, 3554 .

[2] Chupas, P. J., Ciraolo, M. F., Hanson, J. C. \& Grey, C. P. (2001). J. Am. Chem. Soc. 123, 1694.

[3] Bunge, H. J. (1982). Texture Analysis in Materials Science. London: Butterworth.

[4] Balzar, D. \& Popa, N. C. (2004). Diffraction Analysis of the Microstructure of Materials, edited by E. J. Mittemeijer \& P. Scardi, pp. 125-145. Berlin: Springer.

Keywords: Voronoi partitioning, ToposPro, BVSE-modeling, DFT calculations, high-valent ion conductors. The work was done within Russian Science Foundation project no. 19-73-10026 and Russian Foundation for Basic Research grant no. 20-33-90018. T.L. acknowledges financial support of the German Federal Ministry of Education and Research (R2RBattery: 03SF0542A). Computational facilities of the «Zeolite» supercomputer (Samara Center for Theoretical Materials Science) were utilized for DFT calculations.

Acta Cryst. (2021), A77, C1076 